\title{
Size-control by anion templating in mechanochemical synthesis of hemicucurbiturils in the solid state
}

Sandra Kaabel, ${ }^{\mathrm{a}, \mathrm{b}}$ Robin S. Stein, ${ }^{\mathrm{b}}$ Maria Fomitšenko, ${ }^{\mathrm{a}}$ Ivar Järving, ${ }^{\mathrm{a}}$ Tomislav Friščić, ${ }^{*, \mathrm{~b}}$ and Riina Aav*a

a) Department of Chemistry and Biotechnology, Tallinn University of Technology, Akadeemia tee 15, 12618 Tallinn, Estonia.E-mail: riina.aav@taltech.ee

b) Department of Chemistry, McGill University, 801 Sherbrooke St. W. H3A 0B8, Canada. Email: tomislav.friscic@mcgill.ca

\begin{abstract}
Self-organization is one of the most intriguing phenomena of chemical matter. While the selfassembly of macrocycles and cages in dilute solution has been extensively studied, it remains poorly understood in solvent-free environments. Here, we provide the first example of using anionic templates to achieve selective assembly of differently-sized macrocycles in a solvent-free system. Using the acid-catalyzed synthesis of cyclohexanohemicucurbiturils as a model system, we demonstrate size-controlled quantitative synthesis of 6- or 8-membered macrocycles, taking place via spontaneous anion-directed re-organization of mechanochemically-obtained oligomers in the solid state.
\end{abstract}

\section{Main text}

Mechanochemistry has recently emerged as a versatile, environmentally-friendly alternative to conventional chemical reactivity in solution. ${ }^{1-3}$ Besides offering a cleaner, safer way to conduct chemical transformations, mechanochemistry is also a route to discover new reactions and access materials or molecules that have been difficult or even considered impossible to obtain. Despite recent advances in understanding the kinetics and thermodynamics ${ }^{4}$ of mechanochemical reactions, the factors directing the formation of complex molecular structures ${ }^{5}$ under mechanochemical conditions remain largely unexplored. Whereas solid-state mechanochemical synthesis of self-assembled coordination and covalent cages has been reported, ${ }^{6}$ so far there has been no investigation on how such transformations might be facilitated or directed by molecular templates. $^{7}$

Single-bridged cucurbiturils, hemicucurbiturils, ${ }^{8,9}$ including bambusurils and biotinurils, are macrocyclic hosts formed by anion-templated synthesis, ${ }^{10}$ with use in anion ${ }^{11,12}$ and chirality ${ }^{13-}$ 15 recognition, selective anion transport, ${ }^{16}$ catalysis ${ }^{17}$ and photoinduced electron transfer. ${ }^{18}$ The synthesis of cyclohexanohemicucurbiturils $(\mathbf{c y c H C}[n])^{13,14}$ is based on reversible formation of methylene linkages between ethylene urea monomers and formaldehyde under highly acidic conditions, and has emerged as a robust thermodynamically-driven anion-templated reaction in solution. Consequently, we recognized the formation of hemicucurbiturils as an excellent model system to investigate molecular structure templating in mechanochemistry. 


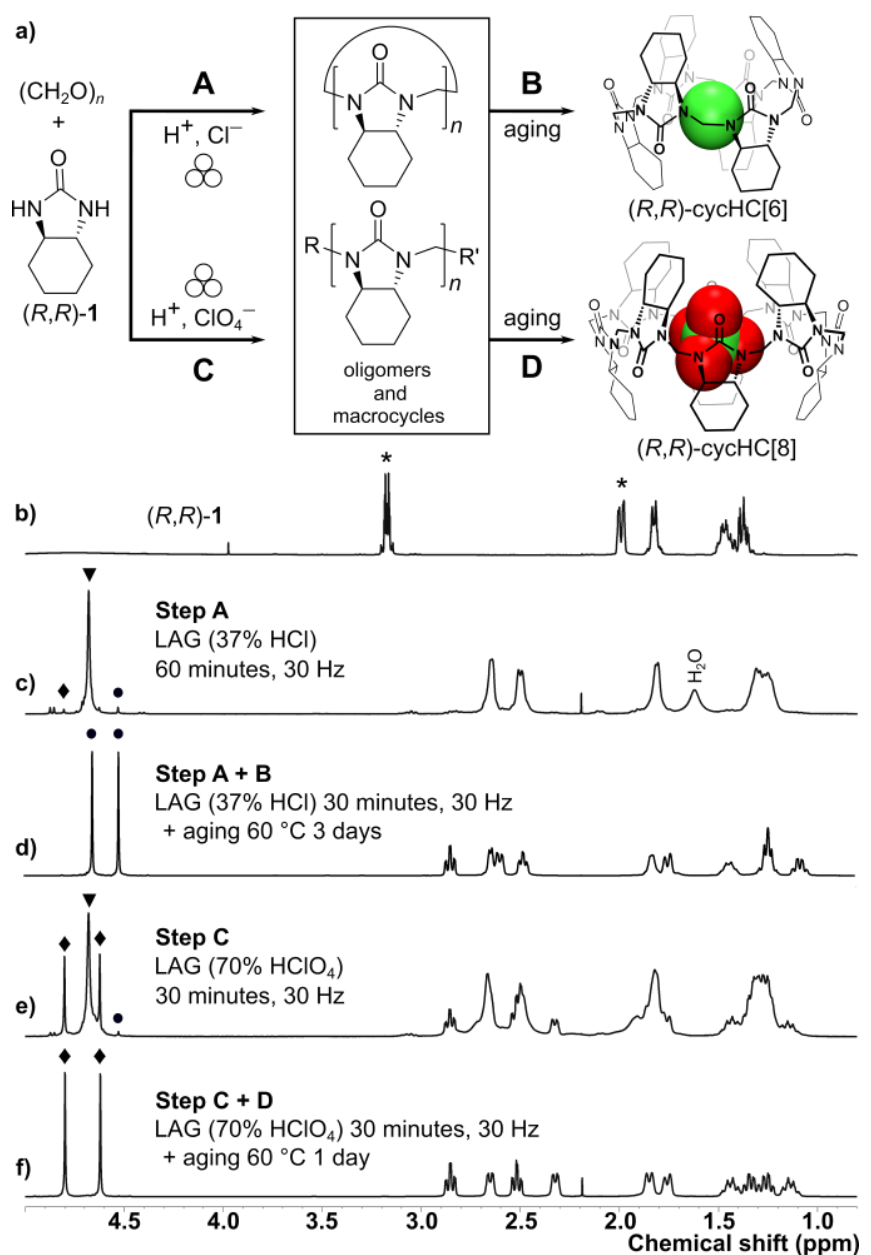

Figure 1. a) Reaction scheme for the templated solid-state synthesis of cycHC[n] macrocycles, coupling liquid assisted grinding (LAG) and aging; ${ }^{1} \mathrm{H}$ NMR spectra of b) starting material (1), c) and e) the reaction mixtures after LAG by steps A (Table 1 line 6) and C (Table 2 line 4) respectively, d) cycHC[6] obtained by route A + B (Table 1 line 4), f) cycHC[8] obtained by route $\mathrm{C}+\mathrm{D}$ (Table 2 line 2). Symbols denote the NMR signals used for the identification of the monomer $(*)$, linear oligomers $(\boldsymbol{\nabla}), \mathbf{c y c H C}[6](\bullet), \mathbf{c y c H C}[8](\bullet)$.

Here we show that mechanical activation and anion templating enable efficient, selective assembly of either 6- or 8-membered cyclohexanohemicucurbituril macrocycles in the solid state (Figure 1). This work represents the first solvent-free route to hemicucurbituril targets and also provides the first clear demonstration of molecular templating in a mechanochemically activated covalent solidstate reaction. It also reveals a surprising process, in which the oligomer structures formed initially by grinding spontaneously re-assemble into well-defined macrocyclic structures.

We first explored the mechanosynthesis of hemicucurbiturils by liquid-assisted grinding (LAG), ${ }^{19} i$. e. milling of equimolar amounts of paraformaldehyde $\left(\mathrm{CH}_{2} \mathrm{O}\right)_{n}$ and $(R, R)$-hexahydro2-benzimidazolinone (1) monomer in the presence of a small amount of concentrated $(37 \%)$ aqueous $\mathrm{HCl}$ (liquid-to-solids ratio ${ }^{20} \eta=0.25 \mu \mathrm{mg}^{-1}$ ). It was expected that the presence of $\mathrm{Cl}^{-}$ ions would encourage the formation of the six-membered macrocycle cycHC[6], as established in solution chemistry. ${ }^{13}$ Ball milling for either 60 or 180 minutes yielded a free-flowing white powder, which was washed with five $2 \mathrm{~mL}$ aliquots of water to remove $\mathrm{HCl}$ and quench the 
reaction. The washed solid was fully soluble in $\mathrm{CHCl}_{3}$ or $\mathrm{CH}_{2} \mathrm{Cl}_{2}$, and ${ }^{1} \mathrm{H} \mathrm{NMR}^{\mathrm{N}}$ analysis in $\mathrm{CDCl}_{3}$ revealed complete disappearance of reactants, along with the appearance of new NMR signals consistent with hemicucurbituril oligomers and a small amount (ca. 5\%) of cycHC[6] (Table 1, line 6, Figure 1c, also Table S1). Identical spectra were obtained if the reaction mixture was immediately dissolved in $\mathrm{CDCl}_{3}$, without washing with water, confirming that all the water-soluble monomer 1 was consumed during milling and that the product composition is consistent before and after quenching.

Analysis of the reaction mixtures by HPLC-MS indicated the formation of linear and macrocyclic oligomeric products ranging from 2 to 15 subunits of $\mathbf{1}$ (see SI). Importantly, milling of the cyclic octamer cycHC[8] in the presence of $\mathrm{HCl}\left(\eta=0.3 \mu \mathrm{mg}^{-1}\right)$ afforded a similar composition of oligomeric products (Table S2), confirming the reversibility of methylene linkages under mechanochemical conditions. Furthermore, this observation indicates that cycHC[6] is not a favored product under the LAG conditions described. The conversion to cycHC[6] remained poor also in the presence of templating chloride or bromide salts, regardless of the choice of catalytic acid (e.g. $\mathrm{HCl}, \mathrm{HBr}, \mathrm{H}_{2} \mathrm{SO}_{4}, \mathrm{HCOOH}$ ) (Table $\mathrm{S} 2$ and $\mathrm{S} 3$ ).

Although LAG did not lead directly to the efficient assembly of cycHC[6], we were surprised to find that simply storing ${ }^{21}$ the milled unquenched reaction mixture in a sealed vial at $45^{\circ} \mathrm{C}$ over 6 days led to quantitative formation (98\%) of cycHC[6] (Table 1, line 1) in a solid-tosolid process (Figure 2a,b). After aging, the reaction mixture was a white powder that was washed with water to remove the acid, giving cycHC[6] in quantitative yield. The solid-to-solid reaction was accelerated by increasing the temperature to $60^{\circ} \mathrm{C}$, affording high conversion (68\%) after one day and full conversion (95\%) to cycHC[6] after two days (Table 1, lines 2, 3). The quantitative conversion to cycHC[6] was reproducibly obtained by aging of products from either 30 or 60 minutes LAG (Table 1 lines 4 and 5, also Table S4). In contrast, milling for only 5 minutes produced waxy, transparent solids (Figure S4) which, upon aging, gave low and inconsistent conversions to cycHC[6] (Table S4, lines 14-15). The mechanochemical step was also explored by manual kneading with aqueous $\mathrm{HCl}$, which revealed that the waxy material results from solidification of an initially formed liquid phase. As the water solubility of oligomeric hemicucurbiturils decreases with the degree of polymerization, we surmise that the waxy material may consist of shorter oligomers. Both the presence of moisture ${ }^{22}$ and $\mathrm{HCl}$ are important for efficient re-assembly of mechanochemically made oligomers into cycHC[6]. For example, no significant conversion to cycHC[6] was obtained after kneading for 5 minutes followed by aging, due to the extensive evaporation of the acid from the mortar prior to the aging step (see SI). Similarly, no cycHC[6] was formed if the aging vessel was not sealed (Table S4 line 5). Selective formation of cycHC[6] was also not observed if $10 \%$ aqueous $\mathrm{HCl}$ was used in LAG $(\eta=0.25 \mu \mathrm{l}$ $\mathrm{mg}^{-1}$ ), presumably due to a lower stoichiometric ratio $(0.75)$ of chloride to cycHC[6] target compared to using concentrated acid (ratio 3) (Table S4 lines 11-13). Moreover, no cycHC[6] was obtained when the oligomers were washed with water to remove $\mathrm{HCl}$ before aging (Figure S1). Overall, these observations are consistent with solid-state formation of cycHC[6] being dependent on the presence of chloride ions.

Table 1. The effect of $\mathrm{LAG}^{\mathrm{a}}$ and aging conditions on the synthesis of cycHC[6] from $\mathbf{1}$ (100 mg, $0.7 \mathrm{mmol})$ and $\left(\mathrm{CH}_{2} \mathrm{O}\right)_{n}(21 \mathrm{mg}, 0.7 \mathrm{mmol})$ in presence of $37 \% \mathrm{HCl},\left(\eta=0.25 \mu \mathrm{L} \mathrm{mg}^{-1}\right.$ ) (Figure 1a, route $A+B)$. 


\begin{tabular}{ccccc}
\hline Entry & $\begin{array}{c}\text { Milling duration } \\
(\text { minutes })\end{array}$ & Aging temperature $\left({ }^{\circ} \mathrm{C}\right)$ & $\begin{array}{c}\text { Aging duration } \\
(\text { days })\end{array}$ & $\begin{array}{c}\text { Conversion } \\
(\%)^{\mathrm{b}}\end{array}$ \\
\hline 1 & 30 & 45 & 6 & 98 \\
2 & 30 & 60 & 1 & 68 \\
3 & 30 & 60 & 2 & 95 \\
4 & 30 & 60 & 3 & 95 \\
5 & 60 & 60 & 3 & 97 \\
6 & 60 & - & - & 5
\end{tabular}

a) Milling was carried out in $10 \mathrm{~mL} \mathrm{ZrO}_{2}$ jars, with a single $10 \mathrm{~mm}$ ball bearing, at $30 \mathrm{~Hz}$; b) conversion to cycHC[6] (\%) determined from ${ }^{1} \mathrm{H}$ NMR spectra after quenching (see SI).

Next, we explored whether a similar LAG and aging strategy could be used to synthesize a larger 8-membered macrocycle, $\mathbf{~ c y c H C [ 8 ] . ~ A s ~ t h e ~ s y n t h e s i s ~ o f ~} \mathbf{c y c H C}[8]$ in solution is conducted in the presence of trifluoroacetic acid, we first explored the solvent-free assembly of cycHC[8] by LAG of 1 and $\left(\mathrm{CH}_{2} \mathrm{O}\right)_{n}$ in the presence of concentrated $\mathrm{CF}_{3} \mathrm{CO}_{2} \mathrm{H}\left(\eta=0.08\right.$ or $0.25 \mu \mathrm{mg}^{-1}$, corresponding to template $\mathrm{CF}_{3} \mathrm{CO}_{2}^{-}$to target macrocycle ratios of 1.5 and 4.4 , respectively), followed by aging (Table S5, lines 11-15). Analysis of the freshly milled reaction mixtures by ${ }^{1} \mathrm{H}$ NMR again revealed the formation of hemicucurbituril oligomers. However, aging gave only poor conversion to cycHC[8], indicating that $\mathrm{CF}_{3} \mathrm{CO}_{2}{ }^{-}$is not a sufficiently strong template to stabilize cycHC[8]. As $\mathrm{CF}_{3} \mathrm{CO}_{2}{ }^{-}$is bound only weakly with cycHC[8] $\left(K_{\mathrm{a}}<10 \mathrm{M}^{-1}\right)$, we next explored the use of a more strongly bound perchlorate $\left(K_{a}=470 \pm 20 \mathrm{M}^{-1}\right){ }^{12}$ Replacing $\mathrm{CF}_{3} \mathrm{CO}_{2} \mathrm{H}$ with $\mathrm{HClO}_{4}$ led to complete, selective conversion to $\mathbf{c y c H C}$ [8]. Specifically, 30-minute milling of equimolar amounts of 1 and $\left(\mathrm{CH}_{2} \mathrm{O}\right)_{n}$ with $70 \%$ aqueous $\mathrm{HClO}_{4}\left(\eta=0.20 \mu \mathrm{mg}^{-1}\right.$, corresponding to a ratio of $\mathrm{HClO}_{4}$ to target cycHC[8] of 3), followed by 1 day aging at 45 or $60{ }^{\circ} \mathrm{C}$ provided $98-99 \%$ conversion to cycHC[8] (Table 2, lines 1 and 2). At room temperature, aging gave $62 \%$ conversion to $\mathbf{c y c H C}[8]$ after 3 days (Table 2, line 3). Surprisingly, we observed that significant conversion to $\mathbf{c y c H C}[8]$ is achieved solely by LAG, indicating that stabilization of $\mathbf{c y c H C}[8]$ via perchlorate under mechanochemical conditions is significantly stronger than the stabilization of $\mathbf{c y c H C}[\mathbf{6}]$ by chloride (Table 2, lines 4 and 5, Figure 1e; Table 1 line 6, Figure 1c). Overall, the formation of cycHC[8] from oligomers in the presence of concentrated $\mathrm{HClO}_{4}$ was found to proceed faster and at lower temperature compared to the formation of $\mathbf{c y c H C}[\mathbf{6}]$ in the presence of concentrated $\mathrm{HCl}$. As the ratio of acid to the target macrocycle in each case is ca. 3, this might be related to the higher acidity of aqueous $\mathrm{HClO}_{4}\left(\mathrm{p} K_{\mathrm{a}}-15.7 \pm 2.0\right)$ compared to $\mathrm{HCl}\left(\mathrm{p} K_{\mathrm{a}}-5.9 \pm 0.4\right)$, enabling faster interconversion of hemicucurbituril oligomers. ${ }^{14,23}$

Table 2. The effect of $\mathrm{LAG}^{\mathrm{a}}$ and aging conditions on the synthesis of $\mathbf{c y c H C}[\mathbf{8}]$ from $\mathbf{1}(100 \mathrm{mg}$, $0.7 \mathrm{mmol})$ and $\left(\mathrm{CH}_{2} \mathrm{O}\right)_{n}(21 \mathrm{mg}, 0.7 \mathrm{mmol})$ in the presence of $70 \% \mathrm{HClO}_{4},\left(\eta=0.2 \mu \mathrm{L} \mathrm{mg}^{-1}\right)$.

\begin{tabular}{ccccc}
\hline Entry & $\begin{array}{c}\text { Milling duration } \\
(\min )\end{array}$ & $\begin{array}{c}\text { Aging temperature } \\
\left({ }^{\circ} \mathrm{C}\right)\end{array}$ & $\begin{array}{c}\text { Aging duration } \\
(\text { days })\end{array}$ & $\begin{array}{c}\text { Conversion } \\
(\%)^{\mathrm{b}}\end{array}$ \\
\hline 1 & 30 & 45 & 1 & 99
\end{tabular}




$\begin{array}{ccccc}2 & 30 & 60 & 1 & 98 \\ 3 & 30 & 20 & 3 & 62 \\ 4 & 30 & - & - & 20-30 \\ 5 & 180 & - & - & 63\end{array}$

a) Milling was carried out in $10 \mathrm{~mL} \mathrm{ZrO}_{2}$ jars, with a single $10 \mathrm{~mm}$ ball bearing, at $30 \mathrm{~Hz}$; b) conversion to cycHC[8] (\%) determined from the ${ }^{1} \mathrm{H}$ NMR spectra of the quenched reaction products (See SI).

The reaction mixtures before and after the solid-to-solid aging step were powders (Figures 2a,b), and were characterized by powder X-ray diffraction (PXRD, see SI), Fourier-transform infrared attenuated total reflectance (FTIR-ATR, see SI) spectroscopy and scanning electron microscopy (SEM, Figure 2c,d). The PXRD patterns for the reaction mixtures immediately after milling are featureless but develop well-resolved Bragg reflections by aging, indicating the formation of a crystalline phase.
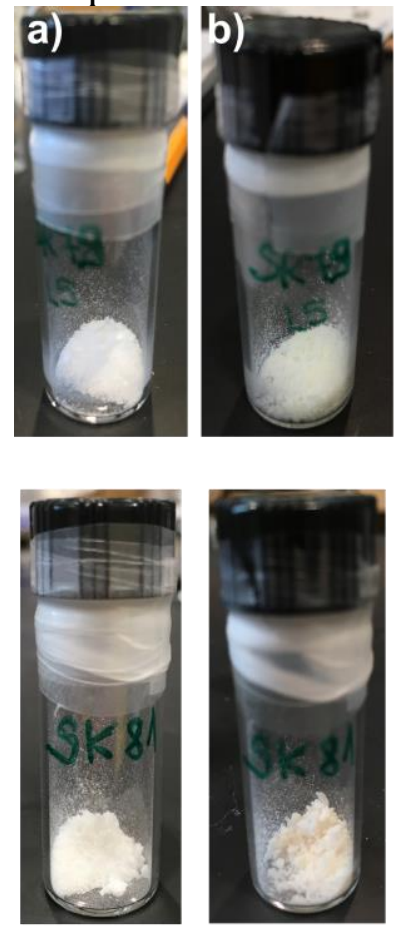

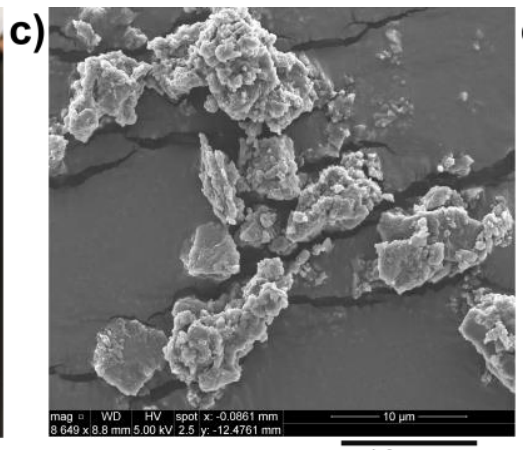

$10 \mu \mathrm{m}$

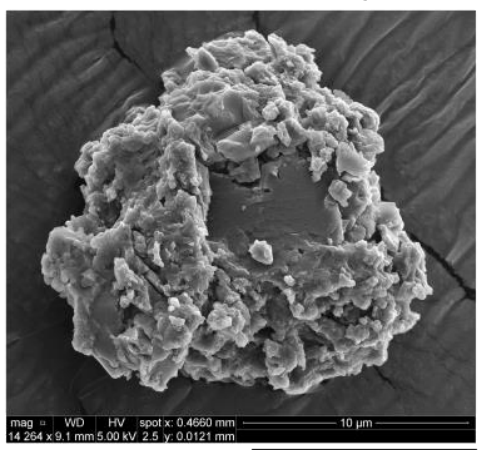

$10 \mu \mathrm{m}$
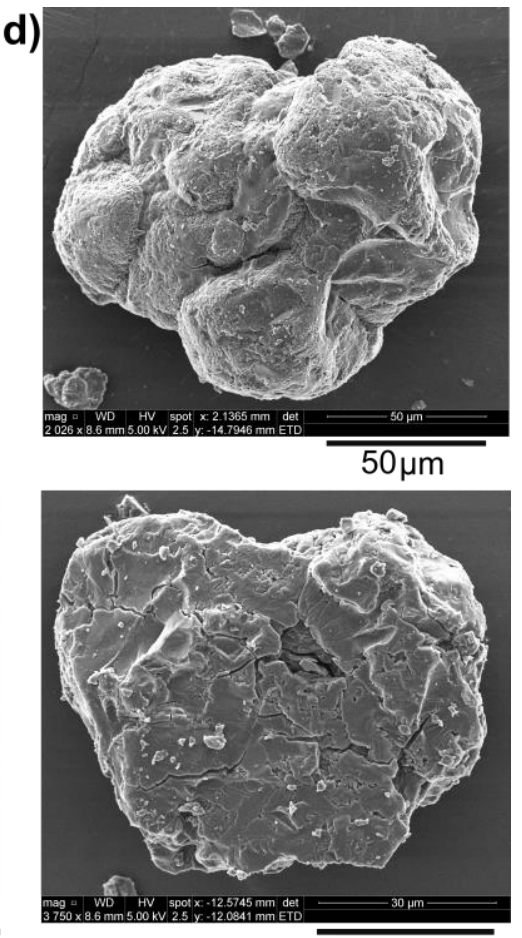

$30 \mu \mathrm{m}$

Figure 2 a) Photos of the reaction mixtures transferred into a vial after 30-minute ball milling and b) after subsequent aging at $60{ }^{\circ} \mathrm{C}$. c) SEM micrographs of the reaction mixtures after 30-minute ball milling and d) after aging at $45{ }^{\circ} \mathrm{C}$ for a week. Top row: cycHC[6] synthesis, bottom row: cycHC[8] synthesis.

For the synthesis of cycHC[6], the PXRD pattern after aging matched to that of cycHC[6] synthesized from aqueous solution. Analysis of SEM images (Figure 2c) also reveals that aging at $45^{\circ} \mathrm{C}$ leads to an increase in particle size, consistent with an Ostwald ripening process, from up to $25 \mu \mathrm{m}$ in the freshly milled solids to no more than $150 \mu \mathrm{m}$ in the final product. Attempts to follow the solid-state formation of $\mathbf{c y c H C}[\mathbf{6}]$ and $\mathbf{c y c H C}[8]$ in situ by PXRD were not successful due to 
difficulty in maintaining a controlled environment of acid, temperature and humidity. Instead, we conducted preliminary real-time monitoring ${ }^{24}$ of solid-state formation of the macrocycles by ${ }^{13} \mathrm{C}$ cross-polarization magic angle spinning (CP-MAS) solid-state NMR (SSNMR) spectroscopy. For this purpose, solid powders obtained by 30 -minute milling of equimolar amounts of $\mathbf{1}$ and $\left(\mathrm{CH}_{2} \mathrm{O}\right)_{n}$ with either aqueous $\mathrm{HCl}$ or $\mathrm{HClO}_{4}$ were packed into SSNMR zirconia rotors, and spectra acquired at fixed time intervals: every 30 minutes in case of cycHC[6] and every 3.75 minutes for the faster synthesis of cycHC[8] (See SI). The CP-MAS parameters used (notably, 4 ms contact time) enabled the selective detection of the signals of the more rigid macrocyclic product, without overlap from the amorphous oligomers, which were apparently highly dynamic in the moist acidic conditions present in the reaction mixture. ${ }^{25}$ As a result, no signal was observed at the outset of CP-MAS monitoring, but as the aging proceeded ${ }^{13} \mathrm{C}$ signals of $\mathbf{c y c H C}[6]$ or $\mathbf{c y c H C}[8]$ grew in intensity and demonstrated macrocycle formation (Figure 3a). Kinetic profiles for the formation of both macrocycles appear to follow a first-order kinetic rate law. (Figure 3b, also see SI).
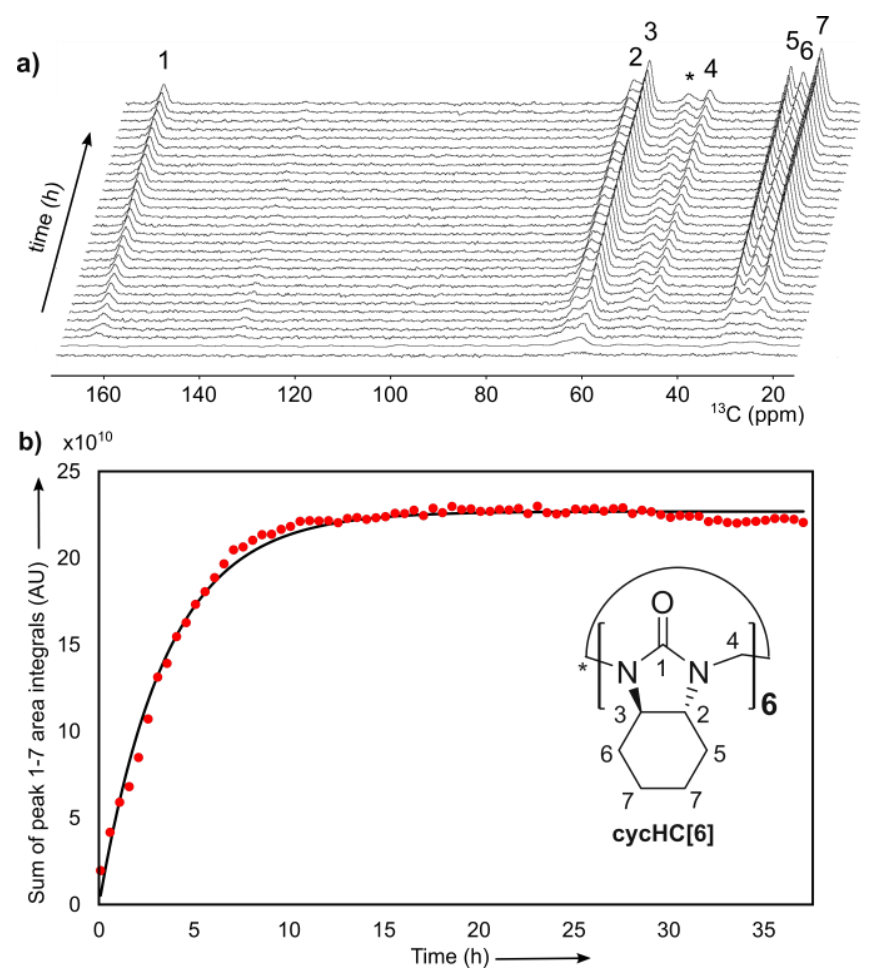

Figure 3. Formation of cycHC[6] by aging monitored in situ by CP-MAS ${ }^{13}$ C SSNMR: a) Stacked consecutive spectra (time interval $30 \mathrm{~min}$ ), indicating the ${ }^{13} \mathrm{C}$ signals of cycHC[6] (1-7) used for curve fitting. b) Kinetic profile for $\mathrm{HCl}$-directed formation of cycHC[6] in the SSNMR rotor, with each datapoint corresponding to the sum of integrated areas of signals 1-7.

First-order kinetics was previously observed in solution synthesis of $\mathbf{c y c H C}[\boldsymbol{n}],{ }^{14}$ which suggests that factors underlying the solid-state assembly of hemicucurbituril macrocycles resemble those controlling their solution-based synthesis. In the SSNMR rotor, the conversion to cycHC[6] reached a plateau in $\sim 11$ hours, with a rate constant $k=7.85 \pm 0.14 \cdot 10^{-5} \mathrm{~s}^{-1}$. After quenching with water and dissolution in $\mathrm{CDCl}_{3},{ }^{1} \mathrm{H}$ NMR analysis revealed $71 \%$ conversion to cycHC[6]. Formation of cycHC[8] was much faster, reaching a plateau after $\sim 1$ hour. After quenching with water and dissolution in $\mathrm{CDCl}_{3},{ }^{1} \mathrm{H}$ NMR analysis revealed $80 \%$ conversion to cycHC[8]. The rate of formation of cycHC[8] is $k=1.47 \pm 0.38 \cdot 10^{-3} \mathrm{~s}^{-1}$, an order of magnitude higher than for 
cycHC[6]. Incomplete conversion of oligomers to $\mathbf{c y c H C}[\boldsymbol{n}]$ in the NMR rotor, which contrast quantitative conversions observed in sealed vials, could be due to inhomogeneous distribution of the solids and liquid additive in the rotor during high-speed spinning $\left(3000 \mathrm{~s}^{-1}\right){ }^{26}$

In summary, we have shown that solid-state assembly of six- and eight-membered hemicucurbituril macrocycles can be achieved selectively and quantitatively using either $\mathrm{HCl}$ or $\mathrm{HClO}_{4}$, respectively, as additives, providing the first clear example of templating in solid-state assembly of macrocycles. While mechanochemical milling of starting materials leads to the formation of solid mixtures of oligomers, upon aging in the presence of a suitable template these powders spontaneously and quantitatively convert to the particular macrocyclic product dictated by the choice of acid additive. In solution, the macrocyclization reaction equilibrium is known to be governed by the formation of an anion inclusion complex, ${ }^{14}$ which appears to be suppressed under mechanochemical conditions, but becomes prevalent during aging. These results, we believe, provide an impressive demonstration of the dynamic behavior and self-assembly in organic solids, and could potentially be adapted for a cleaner, more efficient, selective synthesis of other macrocycles, reducing the need for solvent and acid additives at least a 100-fold.

\section{Experimental section}

Details of experimental procedures are given in the Supporting Information (SI), along with relevant solution ${ }^{1} \mathrm{H}$ and ${ }^{13} \mathrm{C}$ NMR spectra in $\mathrm{CDCl}_{3}$, solid-state CP-MAS ${ }^{13} \mathrm{C}$ NMR spectra and fitting curves for the in situ aging reactions, PXRD patterns, FTIR-ATR spectra, SEM images, as well as HPLC chromatograms and MS data.

\section{Acknowledgments}

We thank Ms. K. A. Mishra for the synthesis of $\mathbf{1}$ and the Estonian Ministry of Education and Research (Grant Nos. IUT 19-32, PUT692), the Centre of Excellence in Molecular Cell Engineering (2014-2020.4.01.15-0013) and the European Regional Development Fund Dora Pluss for financial support. We thank the Canada Foundation for Innovation (CFI), National Science and Engineering Research Council (NSERC) Discovery Grant (RGPIN-2017-06467) and E. W. R. Steacie Memorial Fund (NSERC SMFSU 507347-17) for funding.

\section{References}

1. a) S. L. James, C. J. Adams, C. Bolm, D. Braga, P. Collier, T. Friščić, F. Grepioni, K. D. M. Harris, G. Hyatt, W. Jones, A. Krebs, J. Mack, L. Maini, A. G. Orpen, I. P. Parkin, W. C. Shearouse, J. W. Steed, D. Waddell, Chem. Soc. Rev. 2012, 41, 413-447; b) J.-L. Do, T. Friščić, Synlett 2017, 28, 2066-2092; c) G.-W. Wang, Chem. Soc. Rev. 2013, 42, 7668-7700; d) J. G. Hernández, C. Bolm, J. Org. Chem. 2017, 82, 4007-4019; e) P. Baláž, M. Achimovičová, M. Baláž, P. Billik, Z. Cherkezova-Zheleva, J. M. Criado, F. Delogu, E. Dutková, E. Gaffet, F. J. Gotor, R. Kumar, I. Mitov, T. Rojac, M. Senna, A. Streletskii, K. Wieczorek-Ciurowa, Chem. Soc. Rev. 2013, 42, 7571-7637; f) D. Braga, L. Maini F. Grepioni Chem. Soc. Rev. 2013, 42, 76387648; g) O. Maurin, P. Verdié, G. Subra, F. Lamaty, J. Martinez and T.-X. Métro Beil. J. Org. Chem. 2017, 13, 2087-2093; h) E. Colacino, M. Carta, G. Pia, A. Porcheddu, P. C. Ricci, F. Delogu, ACS Omega 2018, 3, 9196-9209. 
2. a) P. A. Julien, C. Mottillo, T. Friščić, Green Chem. 2017, 19, 2729-2747; b) V. Štrukil, Beil. J. Org. Chem. 2017, 13, 1828-1849.

3. a) N. R. Rightmire, T. P. Hanusa, Dalton Trans. 2016, 45, 2352-2362; b) A. A. Gečiauskaitè, F. Garcia, Beil. J. Org. Chem. 2017, 13, 2068-2077.

4. a) T. Friščić, I. Halasz, P. J. Beldon, A. M. Belenguer, F. Adams, S. A. J. Kimber, V. Honkimäki, R. E. Dinnebier, Nat. Chem. 2013, 5, 66-73; b) H. Kulla, S. Haferkamp, I. Akhmetova, M. Röllig, C. Maierhofer, K. Rademann, F. Emmerling, Angew. Chem. Int. Ed. 2018, 57, 5930-5933; c) A. M. Belenguer, G. I. Lampronti, A. J. Cruz-Cabeza, C. A. Hunter, J. K. M. Sanders, Chem. Sci. 2016, 7, 6617-6627; d) Z. Akimbekov, A. D. Katsenis, G. P. Nagabushana, G. Ayoub, M. Arhangelskis, A. J. Morris, T. Friščić, A. Navrotsky, J. Am. Chem. Soc. 2017, 139, 7952-7957; e) A. M. Belenguer, G. I. Lampronti, N. De Mitri, M. Driver, C. A. Hunter, J. K. M. Sanders J. Am. Chem. Soc. 2018, DOI: 10.1021/jacs.8b08549

5. a) H.-G. Li, G.-W. Wang J. Org. Chem. 2017, 82, 6341-6348; b) S.-Y. Hsueh, K.-W. Cheng, C.-C. Lai, S.-H. Chiu, Angew. Chem. Int. Ed. 2008, 47, 4436-4439.

6. a) B. Içli, N. Christinat, J. Tönnemann, C. Schüttler, R. Scopelliti, K. Severin, J. Am. Chem. Soc. 2009, 3154-3155; b) M. Pascu, A. Ruggi, R. Scopelliti, K. Severin, Chem. Commun. 2013, 49, 45-47; c) J. Antesberger, G. W. V. Cave, M. C. Ferrarelli, M. W. Heaven, C. L. Raston, J. L. Atwood, Chem. Commun. 2005, 892-894; d) J. L. Atwood, M. J. Hardie, C. L. Raston, C. A. Sandoval, Org. Lett. 1999, 1, 164-166; e) B. A. Roberts, G. W. V. Cave, C. L. Raston, J. L. Scott, Green Chem. 2001, 3, 280-284; f) A. Garci, K. J. Castor, J. G. Fakhoury, J.-L. Do, J. Di Trani, P. Chidchob, R. S. Stein, A. K. Mittermeier, T. Friščić, H. Sleiman J. Am. Chem. Soc. 2017, 139, 16913-16922.

7. a) I. Brekalo, C. M. Kane, A. N. Ley, J. R. Ramirez, T. Friščić, K. T. Holman, J. Am. Chem. Soc. 2018, 140, 10104-10108; b) T. Friščić, D. G. Reid, I. Halasz, R. S. Stein, R. E. Dinnebier, M. J. Duer, Angew. Chem. Int. Ed. 2010, 49, 712-715.

8. N. N. Andersen, M. Lisbjerg, K. Eriksen, M. Pittelkow, Isr. J. Chem. 2018, 58, 435-448.

9. a) T. Lizal, V. Sindelar, Isr. J. Chem. 2018, 58, 326-333; b) O. Reany, A. Mohite, E. Keinan, Isr. J. Chem. 2018, 58, 449-460.

10. S. Kaabel, R. Aav, Isr. J. Chem. 2018, 58, 296-313.

11. a) M. A. Yawer, V. Havel, V. Sindelar, Angew. Chem. Int. Ed. 2015, 54, 276-279. b) V. Havel, M. A. Yawer, V. Sindelar, Chem. Commun. 2015, 51, 4666-4669.

12. S. Kaabel, J. Adamson, F. Topić, A. Kiesilä, E. Kalenius, M. Öeren, M. Reimund, E. Prigorchenko, A. Lõokene, H. J. Reich, et al., Chem. Sci. 2017, 8, 2184-2190.

13. R. Aav, E. Shmatova, I. Reile, M. Borissova, F. Topić, K. Rissanen, Org. Lett. 2013, 15, 37863789.

14. E. Prigorchenko, M. Öeren, S. Kaabel, M. Fomitšenko, I. Reile, I. Järving, T. Tamm, F. Topić, K. Rissanen, R. Aav, Chem. Commun. 2015, 51, 10921-4.

15. J. Sokolov, V. Šindelár, Chem. - Eur. J. 2018, 24, 15482-15485.

16. a) M. Lisbjerg, H. Valkenier, B. M. Jessen, H. Al-Kerdi, A. P. Davis,M. Pittelkow, J. Am. Chem. Soc. 2015, 137, 4948-4951. b) C. Lang, A. Mohite, X. Deng, F. Yang, Z. Dong, J. Xu, J. Liu, E. Keinan, O. Reany, Chem. Commun. 2017, 53, 7557-7560. c) A. Šlampová, V. Šindelář, P. Kubáň, Anal. Chim. Acta 2017, 950, 49-56.

17. a) H. Cong, T. Yamato, X. Feng, Z. Tao, J. Mol. Catal. A 2012, 365, 181-185. b) H. Cong, T. Yamato, Z. Tao, New J. Chem. 2013, 37, 3778-3783. c) H. Cong, T. Yamato, Z. Tao, J. Mol. Catal. A 2013, 379, 287-293. 
18. T. Fiala, L. Ludvíková, D. Heger, J. Švec, T. Slanina, L. Vetráková, M. Babiak, M. Nečas, P. Kulhánek, P. Klán, V. Šindeláŕ, J. Am. Chem. Soc. 2017, 139, 2597-2603.

19. a) T. Friščić, A. V. Trask, W. Jones, W. D. S. Motherwell, Angew. Chem. Int. Ed. 2006, 45, 7546-7550; b) G. A. Bowmaker, Chem. Commun. 2013, 49, 334-348.

20. T. Friščić, S. L. Childs, A. A. Rizvi, W. Jones, CrystEngComm 2009, 11, 418-426.

21. C. Mottillo, T. Friščić, Molecules 2017, 22, 144.

22. Estimated maximum water content of the solids before aging, is 2.75 equivalents relative to the monomer 1 when $37 \% \mathrm{HCl}(\mathrm{aq})$ is used and 1.93 equivalents when $70 \% \mathrm{HClO}_{4}(\mathrm{aq})$ is used. This takes into account both the aqueous acid introduced during LAG and the water produced by the condensation reaction.

23. A. Trummal, L. Lipping, I. Kaljurand, I. A. Koppel, I. Leito, J. Phys. Chem. A 2016, 120, 3663-3669.

24. a) P. C. Vioglio, G. Mollica, M. Juramy, C. E. Hughes, P. A. Williams, F. Ziarelli, S. Viel, P. Thureau, K. D. Harris, Angew. Chem Int. Ed. 2018, 57, 6619-6623; b) C. E. Hughes, P. A. Williams, K. D. Harris, Angew. Chem Int. Ed. 2014, 53, 8939-8943.

25. a) M. J. Duer, Introduction to Solid-State NMR Spectroscopy, Blackwell, Oxford, 2004; b) D. C. Apperly, R. K. Harris, P. Hodgkinson, Solid-State NMR: Basic Principles \& Practice, Momentum, New York, 2012; c) I. Matlahov, P. C. A. van der Wel, Methods 2018, 148, 123-135. 26. C. E. Hughes, P. A. Williams, V. L. Keast, V. G. Charalampopoulos, G. R. Edwards-Gau, K. D. M. Harris, Faraday Discuss. 2015, 179, 115-140. 